\title{
NOTAS INTRODUTÓRIAS SOBRE A SOCIOLOGIA CONFIGURACIONAL DE NORBERT ELIAS
}

\author{
Daniel Minuzzi de Souza iD1 e Wanderley Marchi Júnior ${ }^{\text {iD2 }}$
}

\section{Resumo}

Neste artigo revisitamos algumas das principais obras de Norbert Elias com objetivo de apresentar notas introdutórias à sua sociologia configuracional, enfatizando a originalidade e a consistência teórica de seu método e teoria do conhecimento para o estudo de objetos e das relações sociais. Para tanto, sistematizamos a apresentação do estudo em quatro momentos, a saber: introdução; considerações sobre o método; principais conceitos; e considerações finais. Respectivamente, apresentamos elementos sobre a vida e a obra do sociólogo, em seguida, as principais características do método e os conceitos mais importantes desenvolvidos e utilizados pelo autor, para finalmente, apresentar uma síntese conclusiva com destaque ao legado de sua sociologia para o campo acadêmico, em especial a superação da dicotomia indivíduo e sociedade.

Palavras-chave: Configuração; Poder; Sociogênese/Psicogênese; Habitus; Norbert Elias.

\section{INTRODUCTORY NOTES ON NORBERT ELIAS' CONFIGURATIONAL SOCIOLOGY}

\section{Abstract}

In this paper we revisit some of Norbert Elias' main works with the aim objective of presenting introductory notes to his configurational sociology, emphasizing the originality and theoretical consistency of his method and theory of knowledge for the study of objects and social relations. To this end, we have systematized the presentation of the study into four moments, namely: Introduction; considerations on the method; main concepts; and final considerations. Respectively, we present elements about the life and work of the sociologist, then the main characteristics of the method and the most important concepts developed and used by the author. Finally, we present a conclusive synthesis highlighting the legacy of his sociology to the academic field, especially the overcoming of the dichotomy individual and Society.

Keywords: Configuration; Power; Sociogenesis/Psychogenesis; Habitus; Norbert Elias.

\footnotetext{
${ }^{1}$ Doutorando em Educação Física pelo Programa de Pós-Graduação em Educação Física da Universidade Federal do Paraná. PPGDEF/UFPR. Professor do Instituto Federal Catarinense. Integrante do Centro de Pesquisa em Esporte, Lazer e Sociedade (CEPELS).

${ }^{2}$ Professor Titular da Universidade Federal do Paraná. Integrante do Centro de Pesquisa em Esporte, Lazer e Sociedade (CEPELS).
} 


\section{Introdução}

O sociólogo Norbert Elias teve sua importância e grandeza para o campo acadêmico reconhecidos tardiamente. Parece-nos, a sua história de vida, e o tardio reconhecimento, serem exemplos de um processo de longa-duração.

De família judia, nascido em Breslau na Alemanha3, em 1897, pode acompanhar de perto os horrores das duas grandes guerras mundiais. Foi convocado para o exército alemão na primeira guerra mundial e depois viu seus pais serem perseguidos pelo regime Nazista. Assim como outros intelectuais alemães teve que buscar refúgio em outros países. Passou pela Inglaterra, onde teve que recorrer ao comitê de refugiados judeus, fez tentativa de lecionar na Suíça e, posteriormente, na França. Retornou para a Inglaterra, onde veio a ser professor na Universidade de Leicester, mas também teve temporadas como professor convidado em Gana e na Holanda. Se mudou em definitivo para Holanda no ano de 1984, vindo a falecer no ano de 1990, em Amsterdã.

Quanto a sua formação acadêmica, além da sociologia, dedicou-se a estudar medicina, filosofia e psicologia/psicanálise. Um ponto importante sobre a esfera acadêmica diz respeito as passagens pelas cidades de Heidelberguer e Frankufurt, onde se aproximou de Alfred Weber (irmão de Max Weber) e Karl Mannhein (que possuía grande conhecimento da teoria marxista), bem como a experiência em Gana, que Ihe proporcionou conhecer configurações com emoções "mais fortes e imediatas" (ELIAS, 2001, p.77).

A produção de obras de um judeu alemão, contemporâneo do Nazismo é um dado a ser considerado para o seu reconhecimento tardio, por exemplo, a importante obra A Sociedade de Corte, publicada em 1939, só teve sua tradução para a língua inglesa em 1969. O reconhecimento de sua obra deixa um grande legado, principalmente no que diz respeito a superação das dicotomias indivíduo e sociedade, e cuidados necessários para o desenvolvimento de pesquisas sóciohistóricas. Os indivíduos estabelecem relações entre si, que alteram não só a estrutura da sociedade, mas a sua própria estrutura de personalidade. Para explicar o presente precisamos entender o passado, ou melhor, os processos históricos de longa duração, o encadeamento dos acontecimentos, e as mudanças na estrutura, rupturas que para serem compreendidas não podem ser estudadas como fatos isolados, mas a partir da dependência mútua dos indivíduos pertencentes a estas configurações. Nesse sentido, destacamos algumas obras fundamentais para compreender a sociologia eliasiana, quais sejam: A Sociedade de Corte: investigação sobre a sociologia da realeza e da aristocracia de corte; O processo Civilizador (volumes I e II); A Sociedade dos Indivíduos; Introdução à Sociologia; Os Estabelecidos e os Outsiders. Cada uma dessas obras nos deixa um legado sobre o seu método, o seu rigor científico e um novo olhar sobre a história.

As configurações as quais Norbert Elias pertenceu e suas experiências vividas ajudaram-no a delinear um caráter interdisciplinar para a sua teoria do conhecimento, ao memos tempo que demonstram a característica processual do

${ }^{3}$ Atualmente a cidade configura no Estado polonês, e se chama Wroclaw. 
"desenvolvimento". Nesse sentido, poderíamos chamar a sua teoria de uma Sociologia Processual ou uma Sociologia Configuracional.

Para este momento, optamos por utilizar a segunda nomenclatura, de maneira que para nos apropriarmos da Teoria Configuracional de Norbert Elias precisamos compreender o seu método científico e os conceitos que nele operam. Por seguinte, no presente artigo, após uma breve menção à sua vida e obra tratamos de apresentar alguns aspectos do seu método e os conceitos centrais de sua sociologia e, finalmente, apresentamos uma síntese sobre a sua importância para o campo acadêmico. Quanto ao método destacaremos algumas características, quais sejam: Radicalismo Científico; Reflexão profunda (reflexão crítica) para reinterpretação dos fatos; Gênese; Distanciamento; Tarefas do Sociólogo; Encontrar as rupturas na sociedade e tentar explicá-las. No tocante aos conceitos destacaremos os seguintes: Configuração (teias de interdependência); Poder (A balança de poder); Sociogênese/Psicogênese; Processo Cego; Habitus.

\section{Considerações sobre o método eliasiano}

Entendemos que a Sociologia de Norbert Elias se torna uma referência pois apresenta uma consistência teórica-metodológica com seus procedimentos metodológicos e os conceitos operacionais. A importância do estudo empírico, seu olhar crítico sobre a história, a filosofia e a sociologia, denotam a sua grandeza para o campo acadêmico e para o desenvolvimento de uma sociologiahistórica.

O Radicalismo Científico de Norbert Elias pode ser exemplificado com a passagem em que diz que "é fácil perceber que os pressupostos teóricos que implicam a existência de indivíduos ou atos individuais sem a sociedade são tão fictícios quanto outros que implicam a existência das sociedades sem os indivíduos" (ELIAS \& SCOTSON 2000, p. 182).

$\mathrm{Na}$ introdução da obra Introdução à Sociologia, Elias (1980) busca responder as questões "Do que trata a sociologia?" e "Quais mitos caçam os sociólogos?" Ao apontar uma necessidade de reorientação dos conceitos de indivíduo e sociedade, critica os modelos do senso comum que seriam egocêntricos, metafísicos e ideológicos, defendendo a necessidade de a sociologia ter autonomia aos sistemas de crenças e ideologias.

No capítulo II - o sociólogo como destruidor de mitos - Elias (1980), propõem uma perspectiva reflexiva para a Sociologia ao fazer uma crítica a filosofia, ou melhor, ao absolutismo filosófico, por apresentarem concepções falsas e idealizadas de ciência, principalmente por defender conceitos fixos e uma crítica ao relativismo sociológico (que permite mitos e ideologias). A concepção reflexiva de Elias defende uma teoria do conhecimento processual. É preciso entender no desenvolvimento dos conceitos de maneira processual, assim como nas mudanças na estrutura da sociedade e nas estruturas de personalidade dos indivíduos, há uma interdependência mútua que ocorre em processos de longa duração, por isso ir a gênese de maneira empírica é um 
procedimento necessário para passar de um estágio pré-científico para um estágio científico do conhecimento. Também é necessário considerar a autônomia relativa do conhecimento e a necessidade de uma interdisciplinaridade frente a especialização cada vez maior do conhecimento.

A teoria do conhecimento de Elias visa evitar as mentiras e a "fofoca", desviar do campo das mitologias, crenças e desvencilhar as teorias sociológicas das ideologias, em suma, esclarecer as pessoas para terem maior conhecimento sobre mundo. Por isso mesmo ele fica conhecido como caçador de mitos quando defende que toda ideologia é uma mitologia. Em uma passagem da entrevista, transformada no livro Norbert Elias por ele mesmo, quando questionado sobre a necessidade de os homens terem seus mitos (partidos políticos, país, time de futebol) responde que:

Os homens efetivamente precisam de mitos, mas não para comandar sua vida social. Isso não funciona com mitos. Estou profundamente convencido de que os homens conviveriam mais facilmente sem mitos. Os mitos, parece-me, acabam sempre por se vingar (ELIAS, 2001b, p, 48).

Outro elemento importante de sua metodologia se refere a uma reflexão crítica, uma reflexão profunda, em que se utilizando da pesquisa empírica se volta a compreender os processos desde a gênese, mostrando a relação entre a sociogênese e psicogênese para o processo civilizacional, com destaque para o tempo. Quanto mais o tempo passa, mais camadas vão compondo o habitus social. Uma geração vai passando seus comportamentos à próxima. Aos poucos surgem novas camadas e as mais antigas vão deixando de ter a importância que Ihes era atribuída. Em alguns casos a reflexão profunda que Elias se propõe a fazer se utiliza de procedimentos como a pesquisa etnográfica cujo exemplo pode ser visto na obra Os estabelecidos e os Outsiders. Nesse estudo é possível observar a importância do tempo para distinguir os moradores mais antigos dos mais novos da cidade denominada pelo autor como Winston Parva.

Também é importante pontuar a respeito do distanciamento. Em sua concepção sociológica as configurações e os processos contribuem para uma reorientação do que é o conhecimento. O próprio pesquisador faz parte de uma configuração, possui envolvimentos difíceis de compreender, nesse sentido, deve exercer um distanciamento e um auto distanciamento (como parte do conhecimento de si) do objeto. (ELIAS, 2008). O distanciamento também pode ser pensado no sentido de como olhar o passado ou como recorrer à gênese. Seria um erro olhar para o passado a partir da compreensão do tempo atual, um anacronismo. Desta maneira, a pesquisa empírica, como a realizada a partir dos manuais de civilidade 4 , mostra-se acertada para entender o "desenvolvimento" das configurações.

Portanto, para o desenvolvimento de pesquisas sócio-históricas, que se fundamentem na Sociologia Configuracional, é necessário compreender o

\footnotetext{
${ }^{4}$ A exemplo do tratado de Erasmo de Roterdã, intitulado De civilitate morum puerilium (A Civilidade Pueril).
} 
encadeamento dos fatos, identificando e explicando as rupturas que ocorrem nos processos de longa duração. Na medida em que tecemos considerações sobre o método eliasiano vamos percebendo que sua teoria se desenvolve de maneira relacional. Elias, ao nos apresentar as relações interdependentes entre os indivíduos, nos auxilia a percebemos que sua teoria e método são interdependentes aos conceitos, o que lhe garante grande consistência e credibilidade no campo acadêmico. Para compreender melhor esta relação passamos à apresentação dos principais conceitos desenvolvidos pelo sociólogo.

\section{Principais Conceitos}

Na obra $A$ Sociedade de Corte, Elias apresenta algumas questões centrais da sociologia, destacando que:

[...] talvez a questão central, seja saber de que modo e por que os indivíduos estão ligados entre si, constituindo, assim, figurações dinâmicas específicas. Só é possível seguir a pista de uma resposta para tal questão se determinarmos as interdependências entre os indivíduos. (ELIAS, 2001, p. 213-214).

Tal passagem, além de nos mostrar uma das tarefas da sociologia, também nos remete aos conceitos de configuração e, como um de seus desdobramentos, nos remete aos conceitos de interdependência e equilíbrio das tensões.

Configuração foi um termo "cunhado por Elias como contraponto a noção de homo clausus" (LANDINI, 2005a, p.5). Enquanto conceito, configuração ou figuração ${ }^{5}$, se destaca, ao contribuir com uma reorganização da sociologia, no sentido da superação de lógicas dualistas e fragmentárias que separam o indivíduo e a sociedade, o sujeito e o objeto, o micro e macro. Mais do que isso, esse conceito expressa uma perspectiva interdisciplinar de Norbert Elias para pensar os indivíduos que se relacionam em processos de longa duração, não planejados, e que na medida que aumentam a dependência mútua vão refinando os comportamentos e civilizando os costumes, que por sua vez são passados de geração a geração como habitus.

Na obra Introdução à Sociologia, o sociólogo alemão, ao mesmo tempo em que aponta a existência de diversos tipos de configurações, apresenta o conceito como sinônimo de teias de interdependência ao dizer que

[...] pessoas constituem teias de interdependência ou configurações de muitos tipos, tais como famílias, escolas, cidades, estratos sociais ou estados. Cada uma dessas pessoas constitui um ego ou uma pessoa, como muitas vezes se diz numa linguagem reificante. Entre estas pessoas colocamo-nos nós próprios (ELIAS, 1970, p.15-16).

${ }^{5}$ Somente com a carreira mais avançada que Elias começou a questionar "a palavra em si, não seu significado" (LANDINI, 2005b, p.14).

Perspectivas em Diálogo, Naviraí, v. 08, n. 17, p. 08-23, maio/ago. 2021. 
Como já apresentado na introdução deste texto, a formação interdisciplinar de Norbert Elias pode ser observada na formulação de sua sociologia, de maneira que no volume dois de O Processo Civilizador, o sociólogo descreve o conceito de configuração sendo o que articula a sociologia com outros campos do conhecimento.

A fim de entender estruturas e processos sociais, nunca é suficiente estudar um único estrato funcional no campo social. Para serem realmente entendidas, essas estruturas e processos exigem um estudo das relações entre os diferentes estratos funcionais que convivem juntos no campo social e que, com a mais rápida ou mais lenta mudança nas relações de poder provocada por uma estrutura específica desse campo, são no curso do tempo reproduzidas sucessivas vezes. Da mesma forma que em todo estudo psicogenético é necessário levar em conta não só as funções "inconscientes" e "conscientes", mas a contínua circulação de impulsos entre umas e outras, igualmente é importante, em todos os estudos sociogenéticos, levar em conta desde o princípio toda a configuração do campo social, que é mais ou menos diferenciado e carregado de tensões. E só é possível fazer isso porque o tecido social e sua mudança histórica não são caóticos, mas possuem, mesmo numa fase de agitação e desordem, um claro padrão e estrutura. Investigar a totalidade do campo social não significa analisar cada um de seus processos individuais. Implica, acima de tudo, descobrir as estruturas básicas, que dão a todos os processos individuais agindo nesse campo sua direção e marca específica. (ELIAS, 1993, p.239).

A interdependência existente nas diversas configurações também é visível em sua abordagem sociológica. Percebemos a interdisciplinaridade de suas formulações se revelar pelas articulações dos conceitos - que se evidenciam por estudos empíricos - que nos remetem a outros conceitos. Por exemplo, 0 conceito de interdependência guarda relação com os conceitos de equilíbrio de tensões e poder, estando diretamente relacionado à formação da identidade que é processual - dos indivíduos.

Ao descobrirmos as interdependências, reproduzimos a identidade última de todos os indivíduos, sem a qual toda relação humana (mesmo a do pesquisador com o pesquisado, do vivo com o morto) tem algo do período selvagem mais remoto no desenvolvimento da humanidade, algo de bárbaro, dos tempos em que os indivíduos de outras sociedades eram concebidos apenas como estranhos, de fora, muitas vezes nem mesmo como seres humanos. (ELIAS, 2001, p. 215).

A modificação do habitus dos indivíduos, como forma de se diferenciar de antigos padrões de etiqueta e comportamento e na direção de um maior autocontrole, a exemplo do processo de transformação de guerreiros em cortesãos, "tinham um significado intimamente associado ao modo como estava 
sendo negociada a distribuição potencial de poder nas teias de interdependências" (FERREIRA; SOUZA; MARCHI JÚNIOR, 2017, p.19).

Para abordarmos o "equilíbrio das tensões" apresentaremos agora o conceito de poder na obra de Norbert Elias. Na perspectiva do autor, o poder é transitório e se faz presente nas relações de interdependência entre os indivíduos, quanto maior a dependência mútua menor o potencial de poder de um indivíduo em relação aos outros, ou de um grupo sobre o outro, "o poder é uma característica estrutural das relações humanas - de todas as relações humanas" (ELIAS, 1980, p.81).

O modelo de jogos, apresentado por Elias na obra Introdução à Sociologia, demonstra 0 entrelaçamento dos conceitos de configuração, poder e interdependência. Quanto maior for a especialização das funções dos indivíduos pertencentes a determinadas configurações maior será o equilíbrio de poder. Em relações bipolares, entre pais e filhos, ou entre senhor e escravo, o poder pende para o lado dos pais e do senhor, todavia há um poder que o filho exerce sobre os pais e que o escravo exerce sobre o senhor, pois eles entendem haver uma função (valor) no filho ou no escravo, o que pode ser entendido como dependência funcional (ELIAS, 1980).

Em configurações maiores e com funções mais específicas ocorrem relações multipolares em que se nota um maior equilíbrio instável de poder. No seu modelo de jogos Elias em vez de de utilizar o termo relações de poder utiliza "força relativa dos jogadores". Em todo caso fica evidente uma noção de que o poder é relacional.

Metodologicamente, Elias (1980) apresenta sete formas de competição, sendo uma sem regras e seis modelos de jogos com regras, para explicar como as relações de dependência funcional ocorrem em configurações menores (bipolares) e maiores (multipolares).

Para facilitar o entendimento do modelo de jogos de Norbert Elias, sistematizamos um quadro que relaciona o modelo de competição, tipo de interdependência que ocorre no modelo e a distribuição do poder. 
Quadro 1: Sistematização do Modelo de Jogos de Norbert Elias (1980)

\begin{tabular}{|c|c|c|}
\hline MODELO DE COMPETIÇÃO & $\begin{array}{l}\text { TIPO DE } \\
\text { INTERDEPENDÊNCIA }\end{array}$ & $\begin{array}{l}\text { DISTRIBUIÇÃO DE } \\
\text { PODER }\end{array}$ \\
\hline $\begin{array}{l}\text { 1. Competição primária sem } \\
\text { regras }\end{array}$ & $\begin{array}{l}\text { Mútua, recíproca, } \\
\text { estável e para a } \\
\text { sobrevivência }\end{array}$ & $\begin{array}{c}\text { Igual e bilateral } \\
\qquad A \leftrightarrow B\end{array}$ \\
\hline $\begin{array}{l}\text { 2. Jogo de duas pessoas a um só } \\
\text { nível. }\end{array}$ & Mútua e instável. & $\begin{array}{c}\text { Desigual e mutável } \\
\qquad A>B\end{array}$ \\
\hline $\begin{array}{c}\text { 3. Jogo de muitas pessoas a } \\
\text { um só nível }\end{array}$ & $\begin{array}{c}\text { Simultânea e } \\
\text { independente, várias } \\
\text { constelações } \\
\text { individuais }\end{array}$ & $\begin{array}{c}\text { Desigual e não estável. } \\
\qquad \begin{array}{c}>B \\
A>C \\
>D\end{array}\end{array}$ \\
\hline $\begin{array}{l}\text { Jogo multipessoais a vários } \\
\text { níveis }\end{array}$ & $\begin{array}{l}\text { Complexa, funcional, } \\
\text { menor controle entre } \\
\text { os indivíduos, } \\
\text { incontrolável ingresso } \\
\text { e saída de jogadores. }\end{array}$ & 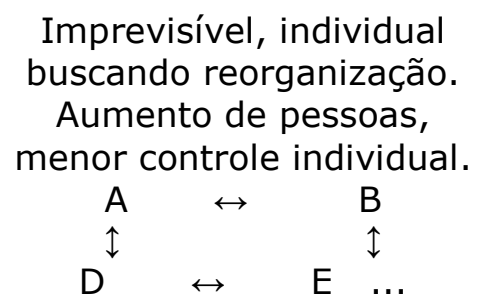 \\
\hline $\begin{array}{l}\text { 5. Jogo de dois níveis: tipo } \\
\text { oligárquico }\end{array}$ & $\begin{array}{c}\text { Complexa, mútua, } \\
\text { instável. } \\
\text { Menor controle do } \\
\text { jogo, várias } \\
\text { constelações. Envolve } \\
\text { alianças, inimizades, } \\
\text { cooperação e } \\
\text { rivalidade. } \\
1^{\circ} \text { grupo: massa } \\
2^{\circ} \text { grupo: } \\
\text { representantes } \\
\end{array}$ & $\begin{array}{l}\text { Diferentes oportunidades } \\
\text { de poder, desproporcional, } \\
\text { rígido e estável. } \\
2^{\circ} \text { grupo menor participa } \\
\text { diretamente (organizado). } \\
1^{\circ} \text { grupo maior não } \\
\text { participa diretamente } \\
\text { (desorganizado). } \\
1^{\circ} \text { grupo }<2^{\circ} \text { grupo }\end{array}$ \\
\hline $\begin{array}{l}\text { 6. Jogo a dois níveis: tipo } \\
\text { democrático }\end{array}$ & $\begin{array}{c}\text { Instável, mútua, } \\
\text { complexa, envolve } \\
\text { constrangimentos e } \\
\text { conflitos. }\end{array}$ & $\begin{array}{c}\text { Flexível e elástico. } \\
\text { Existe um grupo mais } \\
\text { desorganizado, porém } \\
\text { diminui a diferença de } \\
\text { poder entre os dois } \\
\text { grupos. } \\
1^{\circ} \text { grupo } \uparrow \\
2^{\circ} \text { grupo } \uparrow\end{array}$ \\
\hline
\end{tabular}

Fonte: Os autores, 2021.

Importante mencionar que Elias trata de um potencial de poder, e não de um poder absoluto. O potencial de poder guarda relação com as funções que os indivíduos assumem em determinadas configurações, portanto, o poder é transitório e não uma posse que um indivíduo ou grupo utilize para dominar os outros que são considerados inferiores. Nesse sentido, observa-se uma balança de poder.

O potencial e a balança de poder também podem ser observados em Os Estabelecidos e os Outsiders. Nessa obra um elemento importante a ser considerado é o tempo, de maneira mais específica o tempo de moradia em 
determinado local. Os indivíduos estabelecidos, aqueles com mais tempo de moradia (mais que duas gerações), gozam de maior potencial de poder em relação aos outsiders (novos moradores). Nessa configuração ocorrem relações pautadas no carisma e no estigma sendo que

[...] o grupo estabelecido tende a atribuir ao conjunto do grupo outsider as características 'ruins' de sua porção 'pior' - de sua minoria anômica. Em contraste, a auto imagem do grupo estabelecido tende a se modelar em seu setor exemplar, mais 'nômico' ou normativo - na minoria de seus melhores membros (ELIAS; SCOTSON, 2000 p. 22-23).

Ainda tratando do conceito de poder, precisamos trazer elementos referentes a teoria do processo civilizador, como a violência. Tal característica, presente em variadas configurações, nos auxilia na compreensão da relação dos conceitos de poder e equilíbrio das tensões.

A passagem do controle externo ao autocontrole pode ser entendida como um processo de longa duração que pode ocorrer em diferentes escalas e esferas, configurações menores como a família, ou maiores como clubes sociais, cidades, e até mesmo o Estado. Numa configuração familiar, se considerarmos o desenvolvimento de uma criança - desde o seu nascimento passando pela vida adulta e velhice - podemos compreender que este processo civilizador de controle das emoções leva tempo. Aprender comportamentos e tomá-los como seus, como um habitus (segunda natureza), se dá na medida que as relações funcionais de dependência mútua vão se desenvolvendo. O controle das emoções inicialmente ocorre de fora para dentro, controle externo dos indivíduos adultos, para posteriormente ocorrer de dentro para fora, como autocontrole. 0 esporte, a música e a dança, vistos como atividades miméticas exercem um efeito catártico de controle das pulsões auxiliando no autocontrole dos indivíduos. Em uma escala maior, podemos pensar no papel dos clubes sociais e outras organizações da sociedade civil que contribuem nas mudanças de comportamentos dos indivíduos. Nessa perspectiva, não podemos ignorar o papel do Estado moderno no processo civilizador a partir do monopólio dos impostos e o monopólio da violência física.

O Processo Civilizador, é composto por 4 partes, organizada em dois volumes. O volume 1: Uma história dos costumes, é composto por duas partes. $\mathrm{Na}$ primeira parte Elias se dedica a tratar da sociogênese dos conceitos de civilização e cultura, apontando o encadeamento desses conceitos para os processos civilizadores da França, Inglaterra e Alemanha. Na segunda parte do volume 1, com base em diferentes fontes como os manuais de civilidade, pinturas, obras de literatura, entre outas, Elias se dedica a apresentar as mudanças nos padrões de comportamentos, como os costumes vão se transformando desde os costumes medievais, passando pelo comportamento à mesa, mudanças de atitude em relação às funções corporais (assoar-se e escarrar), do comportamento no quarto, mudanças nas relações entre os sexos, até as mudanças na agressividade. No volume 2 intitulado Formação do Estado e Civilização, Elias apresenta, inicialmente, o processo de feudalização e 
formação do Estado ao tratar do monopólio dos impostos e o monopólio da violência. Finalmente, na quarta e última parte da obra Sinopse - sugestões para uma teoria de Processos Civilizadores, Norbert Elias apresenta suas conclusões e sistematiza a apresentação dos seus principais conceitos nos deixando importantes apontamentos e cuidados metodológicos. Em síntese, concordamos com Renato Janine Ribeiro que no prefácio de $O$ Processo Civilizador apresenta a obra como uma história dos sentimentos.

Norbert Elias com a teoria do processo civilizador nos mostra a interdependência entre psicogênese e sociogênese que ocorre em processos históricos de longa duração, no primeiro caso relacionado às alterações das estruturas de personalidade e mudanças no comportamento e, no segundo caso, relacionado às transformações da estrutura social que levaram a formação do Estado moderno. Consequentemente, destacamos outros conceitos para compreender a teoria eliasiana, sendo eles: sociogênese, psicogênese, processo cego e habitus.

A sociogênese pode ser entendida como o processo de formação de uma configuração. Por sua vez, a psicogênese está relacionada às transformações das estruturas de personalidade e dos comportamentos. A relação entre elas se dá concomitantemente uma vez que as alterações nas estruturas da sociedade desencadeiam alterações na estrutura da personalidade e vice-versa. Se faz necessário destacar que estas mudanças (sociogenéticas e psicogenéticas) ocorrem em processos de longa duração. Elias, a partir de estudos empíricos, desenvolve uma sociologia do conhecimento ao demostrar os mecanismos que vão levando às transformações da estrutura da personalidade e comportamentos, na passagem da coação a auto coação desde a sociedade feudal, passando pela sociedade de corte, sociedade burguesa, até chegar à formação do Estado moderno. Portanto, também considera fundamental mecanismos do Estado como o monopólio dos impostos e o monopólio da violência. Estes dois mecanismos possuem um imbricamento. Como engrenagens o funcionamento de um ajuda a manter o do outro: quanto maior a arrecadação de imposto, mais fácil investir em forças de segurança (como exército e polícia), que por sua vez dão mais garantia para o recolhimento e proteção dos tributos. De maneira que o imposto passa a ser entendido como legal, acessível e desejável para administrar, ao passo que o monopólio da violência permite ao administrador pensar a longo prazo. Os monopólios (da terra e da força física) que eram privados, após um processo de longa duração passam a ser utilizados para o benefício de toda a configuração, portanto, se tornam públicos (ELIAS, 1993).

O sociólogo alemão se preocupou em compreender como se deram os processos civilizadores na França, Inglaterra e Alemanha a partir da compreensão da sociogênese dos conceitos de civilização e cultura, e a consolidação do Estado moderno a partir dos monopólios dos impostos e da violência física (ELIAS, 1993; 2011). Nos dois primeiros países, os processos ocorreram de maneiras semelhantes com base no conceito de zivilisation enquanto na Alemanha ocorreu um processo diferenciado, baseado no conceito de Kultur. Sobre esta distinção o sociólogo alemão aponta que 
Enquanto o conceito de civilização inclui a função de dar expressão a uma tendência continuamente expansionista, de grupos colonizadores, o conceito de Kultur reflete a consciência de si mesma de uma nação que teve de buscar e constituir incessante e novamente suas fronteiras, tanto no sentido político como espiritual, e repetidas vezes perguntar a si mesma: "Qual é realmente, nossa identidade?" A orientação do conceito alemão de cultura, com sua tendência a demarcação e ênfase em diferenças, e no seu detalhamento, entre grupos, corresponde a este processo histórico (ELIAS, 2011, p.25).

Os códigos de civilidade, os costumes da aristocracia francesa e sua sociedade de corte se estendem para outras cortes europeias a partir da expansão mercantilista, servindo de modelo de ascensão social a ser seguido pelas classes médias burguesas de França e Inglaterra, o que não ocorre na Alemanha, onde os burgueses pretendiam ascender sem incorporar os valores da aristocracia. Os diferentes contextos geopolíticos destes países também são importantes, sendo conveniente destacar que a Alemanha demorou mais para formar o seu Estado-nação. Havia muitos territórios alvos de disputa, inclusive com a França, o que reforça a construção de uma identidade-nacional alemã que reflete na autoimagem do alemão (ELIAS, 2011).

As mudanças ocorridas, nos indivíduos e na sociedade, em processos de longa duração refletem na autoimagem e na composição social dos indivíduos. Nesse sentido corroboramos com Elias quando diz:

A ideia de que o indivíduo porte em si o habitus de um grupo e de que seja esse habitus o que ele individualiza em maior ou menor grau pode ser definida com um pouco mais de precisão. Em sociedades menos diferenciadas, como os grupos de caçadorescoletores da Idade da Pedra, talvez o habitus social tivesse uma camada única. Nas sociedades mais complexas, tem muitas. [...] É do número de planos interligados de sua sociedade que depende o número de camadas entrelaçadas no habitus social de uma pessoa. Entre elas, uma certa camada costuma ter especial proeminência. Trata-se da camada característica da filiação a determinado grupo social de sobrevivência, como por exemplo uma tribo ou uma nação. Nos membros das sociedades no estágio desenvolutivo dos Estados modernos, isso é designado pela expressão "caráter nacional". Nos membros das sociedades a caminho de se converterem em Estados modernos, as características tribais frequentemente são fáceis de se distinguirem - por exemplo, na Nigéria, o habitus social dos ibos ou dos iorubas. Atualmente ele é mais pronunciado do que os traços comuns a todos os nigerianos, ao passo que, na República Federal da Alemanha, ou na Holanda e na França, apesar de vigorosos movimentos em sentido contrário, as diferenças regionais entre as pessoas estão-se dissipando, comparadas às diferenças nacionais, à medida que a integração avança (ELIAS, 1994, p. 150-151). 
Também importante à sociologia eliasiana é o conceito de Processo Cego, que explica que mudanças ocorridas em processos de longa duração não são planejadas conscientemente, portanto são "cegas". Essas mudanças respeitam uma certa ordem, uma tendência de linearidade, percebida em Estados-nações. Nos Estados mais desenvolvidos há uma tendência de diminuição do diferencial de poder na medida em que ocorre uma especialização das funções especialização do trabalho - e um maior autocontrole das emoções. Os estágios de evolução social 6 tendem a um processo civilizador, mas podem sofrer regressões quando há uma diminuição do autocontrole, aumento do potencial de poder e aumento da violência.

Para facilitar esse entendimento a respeito de "como identificar e medir os diferentes estádios da evolução social" (ELIAS, 1980, p.171) atingido por uma sociedade, Elias nos apresenta uma tríade de controles básicos:

1) Pelo maior ou menor alcance das possibilidades de controlar séries de acontecimentos não humanos - ou seja, o controlo daquilo a que normalmente se chama $<<0$ os acontecimentos naturais $>>$.

2) Pelo maior ou menor alcance das possibilidades de controlar relações interpessoais - ou seja, aquilo que usualmente se designa por $<<$ relações sociais $>>$.

Pela maior ou menor facilidade com que cada um dos seus membros se controla a si próprio enquanto indivíduo - pois que, por muito dependente que seja dos outros aprendeu desde a infância a controlar-se a um maior ou menor grau (ELIAS, 1980, p.171).

Tais mudanças, que podem ser de curto prazo mas que tendem a uma maior consolidação a longo prazo, são importantes para compreendermos como ocorre um processo de individualização ou as mudanças na balança nós-eu, apresentada por Elias na obra $A$ Sociedade dos indivíduos.

Podemos dizer que a "balança nós-eu" está relacionada ao aumento das relações interdependentes entre os países, bem como ao aumento da dependência mútua entre os indivíduos no Estado. As relações internacionais entre os países aumentam à medida que o desenvolvimento das tecnologias de comunicação e os meios de transporte encurtam as distâncias. Elias (1994), ao fazer uma "viagem" pelo Estado romano (iniciada pela família, passando pelas tribos até chegar ao Estado), demonstra que o uso linguístico do termo "identidade-nós" é maior do que o termo "identidade-eu". Assim como faz em $O$ Processo Civilizador, com os conceitos de civilidade e civilização, Elias trata de apresentar os conceitos e o desenvolvimento dos conceitos (usos dos pronomes eu e nós) de maneira que podemos compreender a identidade como um processo.

\footnotetext{
${ }^{6}$ Evolução para Elias não tem o mesmo sentido de progresso. O sentido do dado ao termo é o de evidenciar mudanças estruturais resultantes de processos de longa duração.
} 
Para Elias, a partir do Renascimento, há um nascimento do indivíduo no sentido de se destacar e se diferenciar, um progresso individual, uma distinção entre a ação individual e coletiva, uma maior separação do público e do privado. A antítese entre indivíduo e sociedade começa a aparecer apenas no século XIX, principalmente ao término da Segunda Guerra Mundial. Até esse momento, sociedade e Estado coincidiam e estavam ligados ao território (demarcação das fronteiras). Com o desenvolvimento das tecnologias de comunicação e de transporte ocorre uma diminuição das distâncias e um aumento da mobilidade individual. Após a Segunda Guerra Mundial, houve um aumento da interpendência e um consequente aumento do medo de ataques mútuos entre Estados, ampliando assim a difusão de modelos de autocontrole dos comportamentos e afetos, evidenciando o chamado processo cego, em que os indivíduos ficam mais impotentes frente aos caminhos do desenvolvimento (ELIAS, 1994). Esse aumento da interdependência entre os Estados pode ser entendido como um sinal para a integração da humanidade, um caminho para uma sociedade dos indivíduos.

Ainda, segundo Elias (1994), a "balança nós-eu" pende para um lado ou para outro dependendo do tipo de sociedade. Nas sociedades mais desenvolvidas a tendência é a "identidade-eu" ser mais forte em relação à "identidade-nós", enquanto nas menos desenvolvidas a balança pende para a "identidade-nós" (mais para membros de uma família do que para indivíduos autônomos).

Nessa esteira, para entender o processo de individualização são importantes os conceitos de habitus social (composição) e "individualização crescente ou decrescente". O eu desprovido do nós revela o crescimento da individualização. Segundo Elias (1994, p.171), "esse enfraquecimento da 'identidade-nós' não tem de maneira alguma, uma difusão uniforme em todo o espectro de camada nós". Vale mencionar que nos Estados ditatoriais há maior coerção externa do que auto coerção, o que dificultaria o processo de individualização. Mesmo em estados democráticos há mecanismos para a manutenção da "identidade-nós", como uma encapsulação, uma vez que a

[...] percepção de si como indivíduos e como representantes de um grupo-nós, como franceses, ingleses, alemães ocidentais, norteamericanos, etc., está destinada a diferentes compartimentos de seu conhecimento, e esses compartimentos mantêm apenas uma comunicação muito tênue entre si. Olhando mais de perto, constata-se que os traços da identidade grupal nacional - aquilo a que chamamos "caráter nacional" - constituem uma camada do habitus social engastada muito profunda e firmemente na estrutura de personalidade do indivíduo. O habitus social, e, portanto, a camada desse habitus que constitui o caráter nacional, certamente não é um enigma. Como formação social, ela é, à semelhança da língua, sólida e firme, mas também é flexível e está longe de ser imutável. A rigor, está sempre em fluxo (ELIAS, 1994, p.171).

O habitus social, formado em processos de longa duração, é composto por muitas camadas o que dificulta considerar que os indivíduos sejam 
completamente autônomos, sendo necessário compreender as configurações em que estão inseridos. Nesse sentido, Elias menciona a necessidade de ampliar as investigações sobre os processos educacionais

[...] que desempenham papel decisivo na formação das imagens do eu e do nós dos jovens lançaria mais luz, e rapidamente, sobre a produção e reprodução das identidades-eu e nós ao longo das gerações. Mostraria como as relações cambiantes de poder, intra e interestatais, influenciam a formação dos sentimentos nessa área. $\mathrm{Na}$ verdade, a manipulação dos sentimentos em relação ao Estado e à nação, ao governo e ao sistema político, é uma técnica muito difundida na práxis social. Em todos os Estados nacionais, as instituições de educação pública são extremamente dedicadas ao aprofundamento e à consolidação de um sentimento-nós exclusivamente baseado na tradição nacional (ELIAS, 1994, p.171).

\section{Considerações finais}

No presente estudo nos propusemos a apresentar, introdutoriamente, os principais conceitos e as algumas das contribuições metodológicas e analíticas da Sociologia Configuracional de Norbert Elias para o campo acadêmico. Para tanto, perpassamos diversas obras do sociólogo, evidenciando a originalidade e consistência teórica-analítica de seu método e teoria do conhecimento.

Elias deixa um grande legado para a ciência ao desenvolver e utilizar conceitos como: Configuração (teias de interdependência); Poder (balança de poder); Sociogênese/Psicogênese; Processo Cego; Habitus. Sua importância para o campo acadêmico também fica evidente por utilizar uma metodologia que se caracteriza por seu radicalismo científico, por sua reflexão profunda e crítica para reinterpretação dos fatos, pela busca das gêneses dos processos, por encontrar as rupturas na sociedade e explicá-las com evidências empíricas, e ao mesmo tempo, por manter o distanciamento do objeto. Nessa esteira, Elias, como um caçador de mitos, nos apresenta uma teoria do conhecimento baseada na superação do senso comum, das mitologias, dos sistemas de crenças e ideologias, cujo grande legado é superação da dicotomia indivíduo e sociedade.

Outro legado de Elias é a Norbert Elias Foundation (Fundação Norbert Elias), idealizada pelo próprio sociólogo que deixou o seu patrimônio (herança) e direitos para o desenvolvimento de pesquisas em ciências sociais. Entre as ações desenvolvidas pela fundação estão a realização, apoio e promoção de conferências, publicações científicas, bolsas de estudo e premiações. O seu legado para o campo científico também pode ser observado pela realização de eventos acadêmicos, como o Simpósio Internacional de Processos Civilizadores (que já contabiliza 18 edições). Em tempo, importa mencionar que Elias também é um dos pioneiros a utilizar o esporte como objeto de estudo da sociologia, sendo assim, um dos criadores da sociologia do esporte. 
Chegando ao fim desse ensaio recorremos a mais uma passagem de Norbert Elias por ele mesmo:

Por razões que ignorei, tive muito cedo a impressão de me encontrar no meio de uma cadeia das gerações: dou minha contribuição, faço as coisas avançarem um pouco, mas me situo numa cadeia de gerações. Eis o que sei fazer, tenho esse talento, e eis por que devo fazer as coisas corretamente. Meu ponto de vista não mudou até hoje. Vejo coisas, e devo tentar colocá-las o melhor possível no papel... A maneira como as coisas continuam depois é tarefa das gerações futuras (ELIAS, 2001b, p.46).

Em uma tentativa de síntese podemos dizer que com o desenvolvimento deste ensaio percebemos que a teoria eliasiana é tão interdisciplinar, quanto a sua formação acadêmica, e que estes aspectos encadeados com as configurações vividas pelo autor deixam um grande legado para a sociedade e para a academia, cabendo as gerações atuais e futuras saberem fazer bom uso de seus ensinamentos.

\section{REFERÊNCIAS}

ELIAS, Norbert. O Processo Civilizador: Volume 1 - uma história dos costumes. Rio de Janeiro: Jorge Zahar 2. Ed., 2011.

ELIAS, Norbert. O Processo Civilizador: Volume 2 - formação do Estado e civilização. Rio de Janeiro: Jorge Zahar Ed., 1993.

ELIAS, Norbert. A Sociedade dos Indivíduos. Rio de Janeiro: Jorge Zahar, 1994.

ELIAS, Norbert. A Sociedade de Corte. Rio de Janeiro: Jorge Zahar Ed., 2001.

ELIAS, Norbert. Norbert Elias por ele mesmo. Rio de Janeiro: Jorge Zahar, 2001b.

ELIAS, Norbert. Introdução à Sociologia. Lisboa: Edições 70, 1980.

ELIAS, Norbert; DUNNING, Eric. A Busca pela Excitação. Lisboa: Difel, 1992.

ELIAS, Norbert; SCOTSON, Johan L. Os Estabelecidos e os Outsiders:

Sociologia das relações de poder a partir de uma pequena comunidade.

Tradução de Vera Ribeiro. Rio de Janeiro: Zahar Editor, 2000.

FERREIRA, Fernando Dandoro Castilho; SOUZA, Juliano de; MARCHI JÚNIOR, Wanderley. O processo de difusão do Kung Fu no Ocidente: entre o sentido de 
perda e a inevitabilidade da perda do sentido. Revista Motrivivência, v. 29, n. 51 , p. 13-27, 2017. Disponível em: https://periodicos.ufsc.br/index.php/motrivivencia/article/view/21758042.2017v29n51p13/34501 Acesso em: 20 de nov. de 2020.

LANDINI, Tatiana Savoia. A sociologia processual de Norbert Elias. In: IX Simpósio Internacional Processo Civilizador - Tecnologia e Civilização, 2005, Ponta Grossa - Paraná. Anais do IX Simpósio Internacional Processo Civilizador, 2005a. Disponível em:http://www.uel.br/grupoestudo/processoscivilizadores/portugues/sitesanais/anais9/artigos/mesa_debat es/art27.pdf Acesso em: 20 de nov. de 2020.

LANDINI, Tatiana Savoia. Horror, honra e direitos: violência sexual contra crianças e adolescentes no século XX. Tese (Doutorado em Sociologia) FFLCH/ USP, São Paulo, 2005b. Disponível em: https://www.teses.usp.br/teses/disponiveis/8/8132/tde-11012006194947/publico/TatianaSavoiaLandini-Doutorado.pdf Acesso em: 20 de nov. de 2020.

Recebido em: 27 de fevereiro de 2021. Aceito em: 03 de junho de 2021. Publicado em: 30 de junho de 2021. 